\title{
Effect of First-Line Antiretroviral Treatment in HIV- Positive Patients on Cd4 Cell Count Response in Boru Meda Hospital, Amhara Regional State, Deisse, Ethiopia, 2013-2018
}

\author{
Abebaw Tegegne Damtie* \\ Pharmacy Department, Dessie Health Science College, Ethiopia
}

Received: 制: October 03, 2018; Published: 制: October 29, 2018

*Corresponding author: Abebaw Tegegne Damtie, Pharmacy Department, Dessie Health Science College, Amhara, Ethiopia

\begin{abstract}
Background: In limited resource countries, the effectiveness of first-line antiretroviral treatment in HIV-positive patients could be measured by its strong predictor, the CD4 count for the initiation of antiretroviral therapy and proper management of disease progress. Even though, in addition to HIV, there are many factors which can influence the CD 4 cell count considered to be constant. Methods: A retrospective cohort study was conducted to examine the response of first-line antiretroviral treatment on CD4 count in HIV-positive patients at 0, 6, 12 and 24 months, who enrolled in the first month of 2013 and followed up to begining-2018.The covariance components model was employed to determine the CD4 count changes over time. Results: A total of 320 ART attendants were used to analyze their data. The majority 294(92.4\%) of the respondents were started AZT based ART regimens, but there was no a significance difference among ART regimens for CD4 cell count.

The mean baseline of CD4 cell count ( 166 cells $/ \mathrm{mm}^{3}$ ) was positive associated ( $\left.\mathrm{p}<0.001\right)$ with CD4 count increment at time of follow ups and was increased to 274 cells $/ \mathrm{mm}^{3}$ significantly $(\mathrm{p}<0.001)$ at six months of initiation of ART. Working functional status and younger age, also contribute for CD4 count significant change. Conclusion: The change in CD 4 count was high at the first 6 month than 12 and 24 month. All ART regimens without significance difference that increased mean CD4 count at the study period. Hence, it can be concluded that ART is effective enough in improving the immune system and slowing the progression of HIV infection to AIDS
\end{abstract}

Keywords: CD4 count; ART; Boru Meda Hospital

\section{Introduction}

Human Immunodeficiency Virus (HIV) destroys specific cells of the body that defend the body against diseases are called CD4 cells $[1,2]$. HIV-positive patients with optimal antiretroviral therapy in the first 6-12 months in ARV naïve and adherent patient with drug susceptible virus, CD4 counts are increase by $>100$ cells $/ \mathrm{mm}^{3}$. Immunologic failure is indicated by a fall in CD 4 counts higher than $50 \%$ from the peak value or a return to, or below, the pre-therapy baseline, or by persistent CD $4<100$ cells $/ \mathrm{mm}^{3}$ [3]. The CD4+ cell count thresholds for ART initiation were recently raised 350 to500 cells $/ \mathrm{ml}$ in the United States, while from 200 to350 cells $/ \mathrm{ml}$ in midand low-income countries [4]. The introduction of ART as a modality of treatment in HIV positives has resulted in a dramatic decrease in AIDS related morbidity and mortality and a great improvement in CD4 count of patients [5]. The aims of this study were to examine the relationship between patterns in CD4 count after initiation of combination antiretroviral treatment in HIV-infected patients.

\section{Methods}

\section{Study Design and Period}

A retrospective cohort study was conducted to assess the effect of ART on CD4 count among adult ART users enrolled in the first month of 2013 and followed up to begining-2018.

\section{Study Area and Population}

The study was conducted at Bour meda Hospital (BMH) ART clinic, located in Dessie town, Amhara regional state, which is far $411 \mathrm{~km}$, away from Addis Ababa the capital city of Ethiopia. The hospital gives ART initiation to the newly diagnosed HIV-infected 
patients after HIV testing with follow up treatment. The study population included HIV positive adults who initiated current first line ART treatment in the BMH.

\section{Sample Size and Sampling Procedure}

All HIV positive adults who initiated ART in the hospital at study period and who had a complete CD4 count measurements at 0, 6, 12 and 24 months all were included. Therefore, 320 patients were taken.

\section{Data Collection Procedures}

The study completely used secondary data. Therefore, a data extraction check-list was adopts and modified the routinely collected data. A baseline WHO stage, functional state, weight and CD4 count data were identified and collected from the registration documents of ART attendants which were collected from each patient at the initiation of ART. Subsequent CD4 count data were also taken from the same sources that were collected from each patient almost every 6 month. Similarly, other characteristics, like socio-demographic (sex and age) and initial regimen were also collected from the registration documents of patients. The data were entered, cleaned, and analyzed using SPSS version 20 statistical software. The CD4 count measurement just before the initiation of ART was considered as a covariate so that there should be at least one $\mathrm{CD} 4$ count reading that would be taken as a response variable after the initiation of ART.

\section{Ethical Considerations}

Prior to study initiation, ethical clearance was obtained from Amhara public health institute. In addition, an official letter was written to BMH from Amhara Regional Health bureau and also permission was sought from BMH medical director to conduct the study. The confidentiality of data collected was maintained by omitting the Name and address of patient and prescriber.

\section{Result}

Socio-demographic, Initial regimens, baseline clinical and immunological status of the respondents. A total of 320 HIV positive records were analyzed. The prevalence of age of study participants in the age group $<35$ years were $150(47.2 \%)$ and more than hafe184 (57.9\%) of them were initiated ART at WHO clinical stage III. Regarding the baseline CD4 cell count 102(32.1\%) of the respondents were $<100$ cells $/ \mathrm{mm}^{3}$. The majority $294(92.4 \%)$ of the respondents were started AZT based ART regimens. More than half of the respondents 198(62.3\%) were female and most 246(77.4\%) of them were Workable (Tables 1-3) and (Figures 1-5).

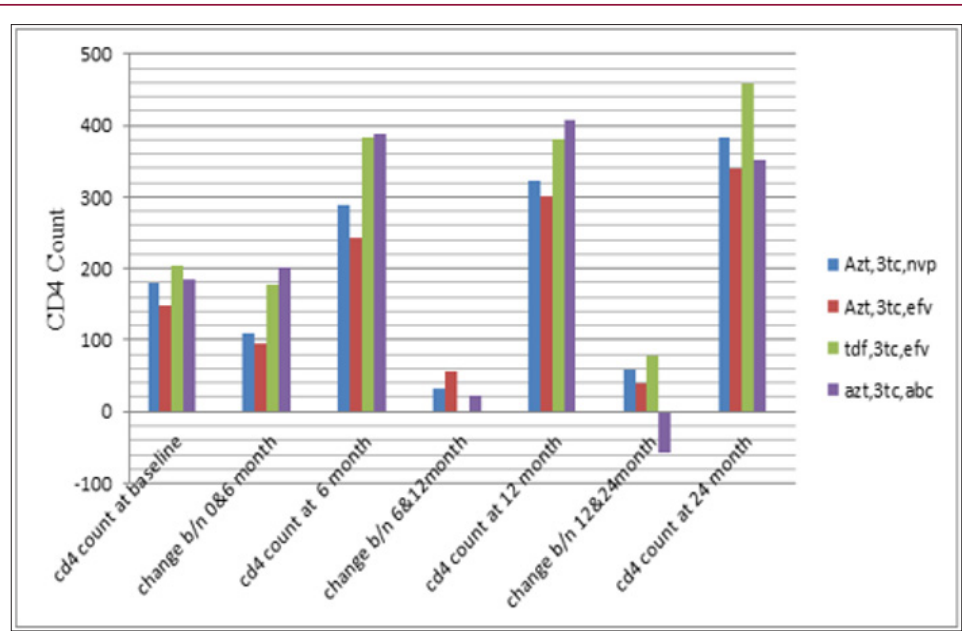

Figure 1: Cd4 pattern on ART regimen.

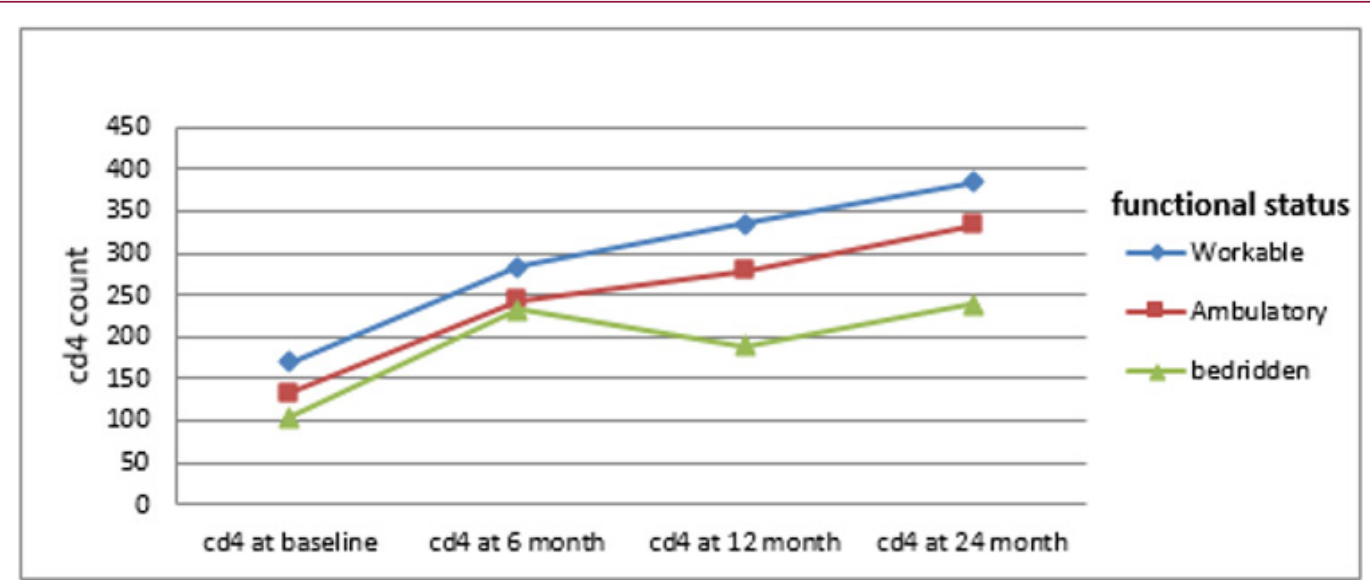

Figure 2: $\mathrm{Cd} 4$ pattern on functional stat. 


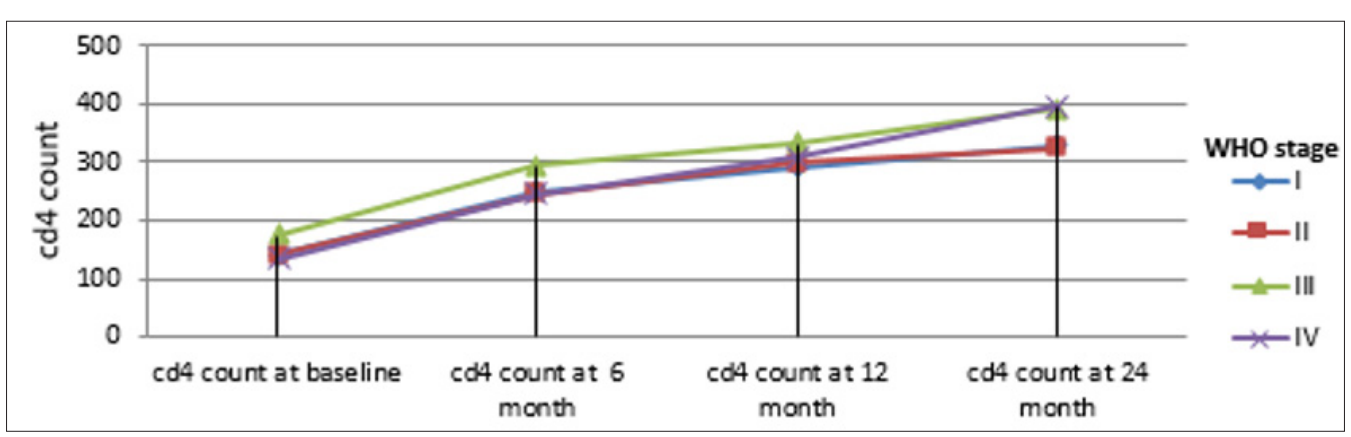

Figure 3: Cd4 pattern on baseline WHO stage.

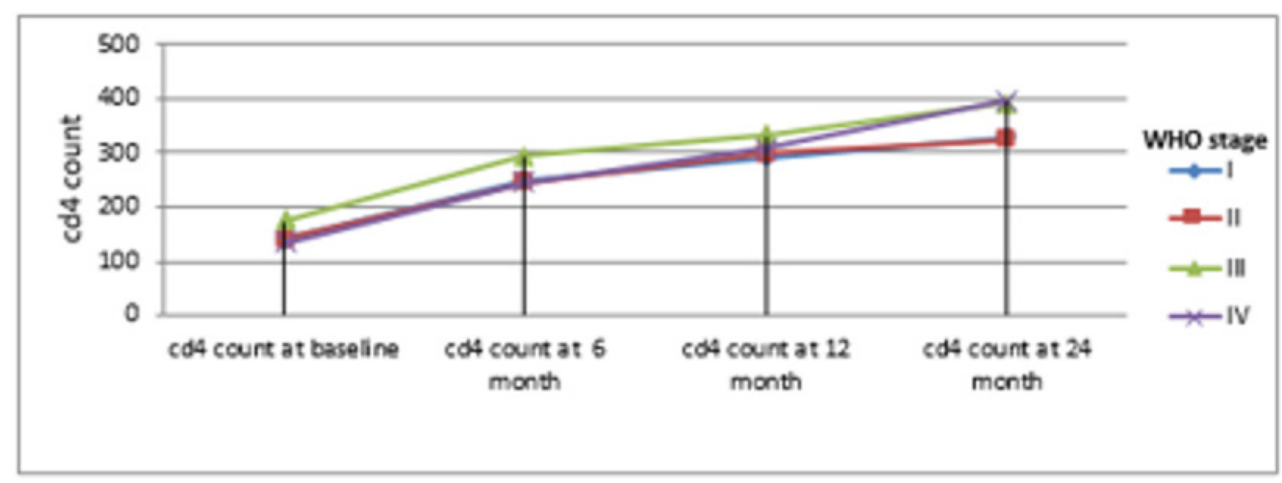

Figure 4: $\mathrm{Cd} 4$ pattern on age.

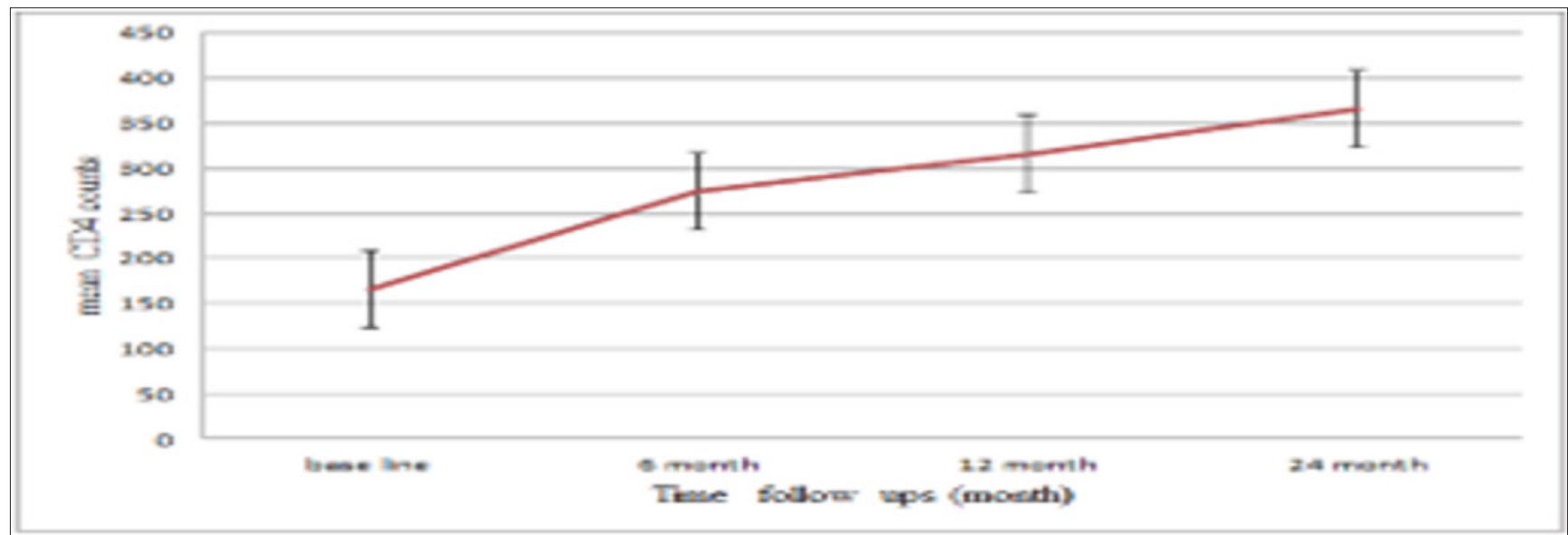

Figure 5: Mean CD4 count at different time intervals.

Table 1: Socio-demographic, Initial regimens, baseline clinical and immunological status of the respondents.

\begin{tabular}{|c|c|c|}
\hline Characteristics & Category & Number (percent) \\
\hline & $<35$ & $150(47.2)$ \\
Baseline age in year & $35-45$ & $150(47.2)$ \\
& $46-55$ & $10(3.1)$ \\
$6(1.9)$ & $2(0.6)$ \\
\hline Sex & $56-65$ & $120(37.7)$ \\
\hline
\end{tabular}




\begin{tabular}{|c|c|c|}
\hline & Workable & $246(77.4)$ \\
Baseline functional status & Ambulatory & 56(17.6) \\
\hline & Bedridden & $36(11.3)$ \\
& Stage I & $76(23.9)$ \\
\hline Baseline WHO clinical stage & Stage II & $184(57.9)$ \\
& Stage III & $20(6.3)$ \\
\hline Initial regimens & Stage IV & $2(0.6)$ \\
& Missing & $132(41.5)$ \\
& Azt,3tc, nvp & $162(50.9)$ \\
& Azt,3tc, efv & $22(6.9)$ \\
& tdf,3tc, efv & $2(0.6)$ \\
\hline Baseline CD4 & azt,3tc, abc & $40(12.6)$ \\
& $<50$ & $102(32.1)$ \\
\hline
\end{tabular}

Mean CD4 cell counts: The Mean CD4 cell counts of female at base line and time of follow up $(173.6 \pm 99.2,286.1 \pm 158.8,319.2 \pm 174.0$ and 375.6 \pm 201.0$)$ were higher than male $(136.0 \pm 85.8,255.6 \pm 126.6,314.3 \pm 172.0$ and $353.0 \pm 184.0)$. According to the age group between 46-55 the Mean CD4 cell counts at 24 month was 391.6 \pm 278.4 and almost closely similar at WHO stage III (390.7 \pm 202.6$)$

Table 2: Mean CD4 cell counts at 0, 6, 12, 24 months.

\begin{tabular}{|c|c|c|c|c|c|}
\hline Variable & variable category & cd 4 count at baseline & $\begin{array}{c}\text { cd4 count at } \\
6 \text { months }\end{array}$ & $\begin{array}{l}\text { cd4 count at } \\
12 \text { months }\end{array}$ & $\begin{array}{c}\text { cd4 count at } \\
24 \text { months }\end{array}$ \\
\hline \multirow{2}{*}{ Sex } & Male & $136.0 \pm 85.8$ & $255.6 \pm 126.6$ & $314.3 \pm 172.0$ & $353.0 \pm 184.0$ \\
\hline & Female & $173.6 \pm 99.2$ & $286.1 \pm 158.8$ & $319.2 \pm 174.0$ & $375.6 \pm 201.0$ \\
\hline \multirow{5}{*}{ Baseline Age (year) } & $<35$ & $163.8 \pm 96.2$ & $288.4 \pm 154.5$ & $326.3 \pm 164.0$ & $377.0 \pm 196.0$ \\
\hline & $35-45$ & $153.9 \pm 82.0$ & $270.2 \pm 134.6$ & $316.2 \pm 173.9$ & $363.7 \pm 182.8$ \\
\hline & $46-55$ & $203.0 \pm 147.7$ & $235.8 \pm 147.6$ & $336.2 \pm 219.7$ & $391.6 \pm 278.4$ \\
\hline & $56-65$ & $166.3 \pm 229.8$ & $174.3 \pm 242.2$ & $186.0 \pm 224.6$ & $278.3 \pm 268.5$ \\
\hline & $>65$ & $6.0 \pm 0.0$ & $57.0 \pm 0.0$ & $31.0 \pm 0.0$ & $48.0 \pm 0.0$ \\
\hline \multirow{4}{*}{$\begin{array}{c}\text { Baseline WHO } \\
\text { stage }\end{array}$} & I & $141.2 \pm 45.7$ & $248.1 \pm 122.7$ & $290.3 \pm 150.4$ & $326.6 \pm 174.8$ \\
\hline & II & $141.4 \pm 92.9$ & $245.9 \pm 129.5$ & $299.2 \pm 161.2$ & $322.7 \pm 159.5$ \\
\hline & III & $173.4 \pm 105.0$ & $294.6 \pm 158.7$ & $331.6 \pm 186.9$ & $390.7 \pm 202.6$ \\
\hline & IV & $133.7 \pm 74.9$ & $243.7 \pm 139.4$ & $307.3 \pm 107.0$ & $396.0 \pm 253.9$ \\
\hline \multirow{4}{*}{$\begin{array}{c}\text { Baseline Functional } \\
\text { state }\end{array}$} & Workable & $169.3 \pm 93.0$ & $284.3 \pm 144.4$ & $334.8 \pm 174.4$ & $383.1 \pm 194.5$ \\
\hline & Ambulatory & $133.0 \pm 96.2$ & $244.0 \pm 147.6$ & $278.0 \pm 152.0$ & $333.0 \pm 185.9$ \\
\hline & Bedridden & $103.4 \pm 109.0$ & $231.5 \pm 189.1$ & $189.3 \pm 150.7$ & $239.0 \pm 176.5$ \\
\hline & Azt,3tc, nvp & $179.8 \pm 159.0$ & $289.7 \pm 151.4$ & $322.3 \pm 172.9$ & $382.2 \pm 207.6$ \\
\hline Initial & Azt,3tc, efv & $148.1 \pm 91.5$ & $243.2 \pm 125.1$ & $300.1 \pm 166.3$ & $340.4 \pm 173.2$ \\
\hline \multirow[t]{2}{*}{ Regimens } & Tdf,3tc, efv & $205.0 \pm 114.2$ & $382.7 \pm 187.1$ & $381.9 \pm 183.3$ & $459.2 \pm 236.7$ \\
\hline & Azt,3tc, abc & $184.5 \pm 135.7$ & $387.0 \pm 273.7$ & $408.5 \pm 313.5$ & $351.5 \pm 174.9$ \\
\hline
\end{tabular}


Table 3: Association of CD4 count at different time interval with baseline Predictors.

\begin{tabular}{|c|c|c|c|c|c|c|}
\hline \multirow{2}{*}{ Predictors } & \multicolumn{2}{|c|}{ At 6 months } & \multicolumn{2}{|c|}{ At 12 months } & \multicolumn{2}{|c|}{ At 24 months } \\
\hline & Coefficient & $P$ value & Coefficient & $P$ value & coefficient & P value \\
\hline Constant & 198.287 & $0.003^{* *}$ & 331.506 & $0.00^{* * *}$ & 336.59 & $0.001^{* *}$ \\
\hline Sex & 10.537 & 0.478 & -24.454 & 0.179 & -8.475 & 0.697 \\
\hline Baseline Age & -28.269 & $0.005^{* *}$ & -21.95 & 0.072 & -21.201 & 0.147 \\
\hline $\begin{array}{c}\text { Baseline WHO } \\
\text { Stage }\end{array}$ & -10.837 & 0.435 & -54.809 & $0.001^{* *}$ & -52.147 & $0.011^{*}$ \\
\hline $\begin{array}{l}\text { Baseline functional } \\
\text { State }\end{array}$ & 18.099 & $0.042^{*}$ & 23.018 & $0.036^{*}$ & 42.109 & $0.001^{* *}$ \\
\hline Initial Regimens & 8.143 & 0.456 & 17.432 & 0.194 & -3.317 & 0.835 \\
\hline Base line CD4 & 0.561 & $0.000^{* * *}$ & 0.6 & $0.000^{* * *}$ & 0.471 & $0.000^{* * *}$ \\
\hline Baseline weight & -0.671 & 0.367 & -1.082 & 0.235 & -0.689 & 0.526 \\
\hline
\end{tabular}

${ }^{*}: \mathrm{p}<0.05,{ }^{* *}: \mathrm{p}<0.01,{ }^{* * *}: \mathrm{p}<0.001$

\section{Discussion}

This study was aimed describing that the response of ART to CD4 cell counts for patients on ART at BMH. In the present study, more than half of the patients initiating ART 198(62.3\%) were females. A similar finding was reported by Lemma Derseh; from Ethiopia, Felege Hiwot Referral Hospital who stated ART were more likely to be females [6]. Latin America, sub-Saharan Africa, Asia [7] and South Africa were similarly reported [8]. In the developing countries females have high prevalence to HIV infection, due to socially and biologically weaker to infect by HIV [9]. Other authors reported that females more likely to be diagnosed for infection earlier, could attend voluntary counseling and testing [10,11], had also better response to ART [12], repeated-testing, and acceptance of linkage to HIV-care after a positive result as compared to males [13-16]. The CD4 count has been commonly used as the main treatment outcome signs for continuation of ART.

The goal of ART is to achieve sustained viral suppression and increased CD4 counts in individuals on treatment. The responses of ART to CD4 cell is determine by viral and host factors, in which individuals having suboptimal increase of CD4 cell count with approximately $15-30 \%$, there are no compliance to ART [6]. In the present study, there was a good immune recovery at the six month of therapy. The mean baseline of CD4 cell count $\left(166\right.$ cells $/ \mathrm{mm}^{3}$ ) was positive associated $(\mathrm{p}<0.001)$ with CD4 count at time of follow ups and was increased to 274 cells $/ \mathrm{mm}^{3}$ significantly $(\mathrm{p}<0.001)$ at six months of imitation of ART. According to the study in Nepal Public Health Laboratory the baseline CD4 count was 155cells/ mm3, which increased to 297cells/mm3 significantly higher than the present study [17]. According to ART management guideline three or more ART drugs are recommended worldwide for the treatment of HIV+ [7].

In this study, showed that the majority 294(92.4\%) of the respondents were started AZT based ART regimens. Most of ART regimens that increase mean CD4 cell count at the time of point of follow up, especially at the first 6 month (minimum 95 cells $/ \mathrm{mm}^{3}$; AZT+3TC+EFV---Maximum 202.5 cells/mm3; AZT+3TC+ABC), but there was no a significance difference among ART regimens for sustain increasing the CD4 cell count. Similarly reported by Patel et al. study, both NVP and EFV at any given point of time there was no significance difference in the rate of increase of CD4 count [9]. In contrast after 6 months of therapy there is significant rise of CD4 count in Nevirapine $(p<0.001)$ regimens than in Efavirenz ( $p>$ 0.05) regimens [6]. According to Baseline WHO clinical stages the majority 184(57.9\%) started treatment in late stages of the disease (stage III). On the other studies conducted in Addis Ababa, yekatit 12 hospital 465 (52.4\%) and south Africa majority of HIV+ started ART treatment at the stage of III and IV $[6,18]$.

Regarding baseline functional states were showed that a significance change on CD4 cell count at each time of follow ups, also this is supported by other studies done in north- west and eastern Ethiopia [7,19]. Patients who started ART at working status had a good immune response in the study period of time than ambulatory/bedridden, similar finding also reported by other study [7]. The CD4 count measurements could affect by opportunistic infections at the start of ART and treatment period over time [20]. There was a significant $(\mathrm{p}<0.05)$ association between Baseline age and $\mathrm{Cd} 4$ counts at six month. At older baseline age the $\mathrm{Cd} 4$ count was decreased by -28.269 coefficients as compared to younger age. Different authors stated that younger age more reasoned out on CD4 cell recovery [21]. ART treatment response for older persons was poor [22] and come to the clinic late [23,24]. In contrast, other authors reported there was no any significance association between age and CD 4 count increment $[7,20,21,25,26]$.

\section{Limitations}

In this paper some limitations that should be considered. The study was retrospective design, so it is difficult to get some relevant variables full information from record book and patients' card especially clinical characteristics, nutritional status and educational status.

\section{Conclusion}

This study had shown, higher baseline CD4 count, contributed to great significant $(\mathrm{p}<0.001)$ increment of CD4 count. The change in CD4 count was high at the first 6 month than 12 and 24 month. 
Working functional status and younger age, also contribute for CD4 count change. All ART regimens without significance difference that increased mean cd 4 count at the study period. Hence, it can be concluded that ART is effective enough in improving the immune system and slowing the progression of HIV infection to AIDS.

\section{References}

1. (2003) Control CFD, Centers for Disease Control and Prevention, US.

2. Markowitz SB (2007) Environmental and occupational medicine. Wolters Kluwer/Lippincott Williams \& Wilkins.

3. (2009) National Centre for AIDS \& STD Control. National anti-retroviral therapy guidelines, Government of Nepal, Ministry of Health \& Population, Kathmandu.

4. R Chris Rathbun, PharmD, BCPS, AQ ID, (2013) AAHIVE Antiretroviral Therapy for HIV Infection.

5. FJJ Palella, KM Delaney, AC Moorman, Loveless MO, Fuhrer J, et al. (1998) Declining morbidity and mortality among patients with advanced human immunodeficiency virus infection. HIV outpatient study investigators. The New England Journal of Medicine 338(13): 853-860.

6. K Suresh Babu, Ch Ram Babu, N Baratha Jyothi, K Sunita (2014) A retrospective study on status of CD4 counts and effect of ART in patients attending VCTC of MGM Hospital, IOSR Journal of Nursing and Health Science 3(6): 2320-1940

7. Lemma Derseh Gezie (2016) Predictors of CD4 count over time among HIV patients-initiated ART in Felege Hiwot Referral Hospital, northwest Ethiopia: multilevel analysis. BMC Research Notes 9: 377.

8. Denis Nash, Monica Katyal, Martin, WG Brinkhof, Keiser O, et al. (2008) Long-term immunologic response to antiretroviral therapy in lowincome countries: Collaborative analysis of prospective studies AIDS, 22(17): 2291-2302.

9. Palmer BE, Boritz E, Blyveis N, Wilson CC, (2002) Discordance between frequencies of human Immunodeficiency virus type 1 (HIV-1)-specific gamma interferon-producing CD4 (+) T cells And HIV-1-specific lymphoproliferation in HIV-1-infected subjects with active viral Replication Virol 76(12): 5925-5936.

10. (1994) European collaborative study material history of vertically acquired human Immunodeficiency virus infection pediatrics 94: 815819.

11. Kwobach CM, Braitstein P, Koech JK, Simiyu G, Mwanqi AW, et al. (2015) Factors associated with late engagement to HIV care in Western Kenya: a cross-sectional study. J Int Assoc Provid AIDS Care.

12. Mojumdar K, Vajpayee M, Chauhan N, Mendiratta S (2010) Late presenters to HIV care and treatment, identification of associated risk factors in HIV-1 infected Indian population. BMC Public Health 10: 416.

13. Addisu A, Dagim A, Tadele E, Adissu A, Mussie A, et al. (2015) CD4 cell count trends after commencement of antiretroviral therapy among HIV

ISSN: 2574-1241

DOI: 10.26717/BJSTR.2018.10.001974

Abebaw Tegegne Damtie. Biomed J Sci \& Tech Res

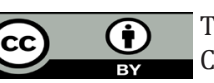

This work is licensed under Creative Commons Attribution 4.0 License

Submission Link: https://biomedres.us/submit-manuscript.php infected patients in Tigray, northern Ethiopia: a retrospective crosssectional study. PLoS ONE 10(3).

14. Galdas PM, Cheater F, Marshall P (2005) Men and health help-seeking behaviour:l iterature review. J Adv Nurs 49(6): 616-623.

15. Cornell M, Schomaker M, Garone DB, Giddy J, Hoffmann CJ, et al. (2012) Gender differences in survival among adult patients starting antiretroviral therapy in South Africa: a multicentre cohort study. PLoS Med p. 9.

16. Madec Y, Laureillard D, Pinoges L, Fernandez M, Prak N, et al. (2007) Response to highly active antiretroviral therapy among severely immuno-compromised HIV-infected patients in Cambodia. AIDS 21: 351-359.

17. MacPherson P, Moshabela M, Martinson N, Pronyk P (2009) Mortality and loss to follow-up among HAART initiators in rural South Africa. Trans R Soc Trop Med Hyg 103: 588-593.

18. Majid D, Leigh A Shaferc, S C, Ken K, Yoav K (2018) Rapid CD4 decline prior to antiretroviral therapy predicts subsequent failure to reconstitute despite HIV viral suppression. Journal of Infection and Public Health 11: 265-269.

19. Wasti SP, Simkhada P, Randall J, Freeman JV, Van Teijlingen E (2012) Barriers to and facilitators of antiretroviral therapy adherence in Nepal: a qualitative study S. J Health Popul Nutr 30(4): 410-419.

20. Reda AA, Biadgilign S, Deribew A, Gebre B, Deribe K (2013) Predictors of change in CD4 lymphocyte count and weight among HIV infected patients on anti-retroviral treatment in Ethiopia: a retrospective longitudinal study. PLoS ONE 8(4)

21. Kim KH, Yi J, Lee HS (2015) The CD4 slope can be a predictor of immunologic recovery in advanced HIV Patients: a case control study. J Intern Med 30(5): 705.

22. Viard PJ, Mocroft A, Chiesi A, Kirk O, Røge B, Panos G, et al. (2001) Influence of age on $\mathrm{CD} 4$ cell recovery in human immunodeficiency virusinfected patients receiving highly active antiretroviral therapy: evidence from the Euro SIDA study. J Infect Dis, 183: 1290-1294.

23. (1999) Gea Banacloche J, LH LC. Immune reconstitution in HIV infection. AIDS, 13(Suppl A): S25-38.

24. Kwobach CM, Braitstein P, Koech JK, Simiyu G, Mwanqi AW, et al. (2015) Factors associated with late engagement to HIV care in Western Kenya: a cross-sectional study. J Int Assoc Provid AIDS Care.

25. Florence E, Lundgren J, Dreezen C, Fischer M, Kirk O, et al. (2003) Factors associated with a reduced $\mathrm{CD} 4+$ lymphocyte count response to HAART despite full viral suppression in the Euro SIDA study. HIV Med, 4(3): 255-262.

26. Smith JC, Sabin AC, Youle SM, Loes KS, Lampe CF, et al. (2004) Factors influencing increases in CD4 cell counts of HIV positive persons receiving long-term highly active antiretroviral therapy. J Infect Dis 190: $1860-1868$

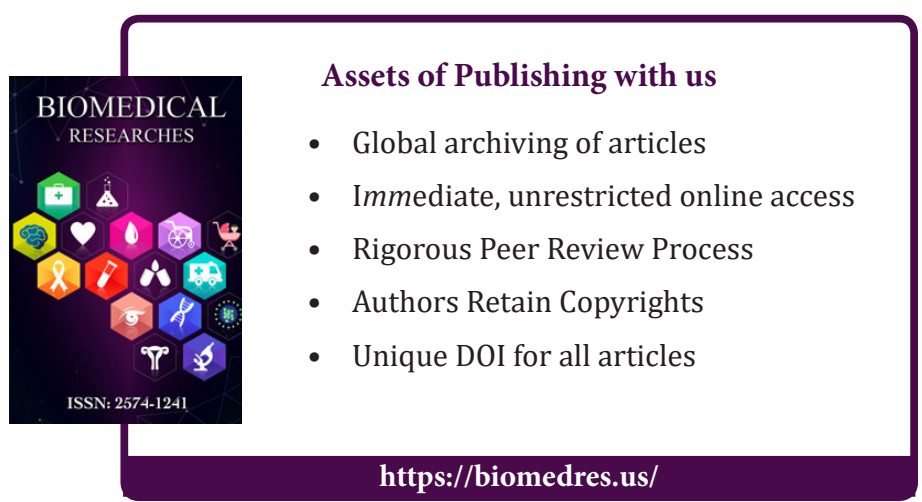

Cite this article: Abebaw Tegegne D. Effect of First-Line Antiretroviral Treatment in HIV-Positive Patients on Cd4 Cell Count Response in Boru Meda Hospital, Amhara Regional State, Deisse, Ethiopia, 2013-2018. Biomed J Sci\&Tech Res 10(4)-2018. BJSTR. MS.ID.001974. DOI: 10.26717/ BJSTR.2018.10.001974. 